\title{
Maternal responsiveness and directiveness in speech to 2- year-olds: relationships with children's concurrent and later vocabulary
}

\begin{abstract}
This study investigated responsive and directive speech from 60 Finnish mothers to their 2-year-old children, as well as correlations with concurrent and later vocabulary. Possible gender differences both with regard to maternal speech as well as children's vocabulary skills were considered. There were no gender differences in maternal utterance frequencies or in maternal utterance types. Girls scored statistically significantly higher in receptive and expressive vocabulary tests at 24, 30 and 36 months. The effect sizes were large. Maternal Other Utterances (fillers, like yes, oh, umm) were correlated with children's concurrent receptive vocabulary. However, there was no relationship between Other Utterances and children's later vocabulary after controlling for vocabulary size at 24 months. This association may reflect an attempt by mothers to elicit speech from more linguistically advanced children. Furthermore, mothers' Intrusive Directives towards 2year-olds correlated negatively with receptive vocabulary at 30 months, particularly for boys. Surprisingly, Intrusive Attentional Directives correlated positively with expressive vocabulary in the group of 30-month-old girls. The results of this study demonstrate relationships between maternal verbal interactional style and both concurrent and future child vocabulary.
\end{abstract}

The final authenticated version is available online: https://doi.org/10.1177/01427237211049585 


\section{INTRODUCTION}

Vocabulary at 3 years is strongly associated with later linguistic, academic and reading performance (Harlaar et al., 2008; Hart \& Risley, 1995). It is known that linguistic development is supported and shaped by both neurobiology and the environment (Oliver et al., 2004). Parent-child interaction has been proposed to be one of the best predictors of the vocabulary abilities of the child around the onset of word production (Hoff, 2006; Tamis-LeMonda et al., 2019; Tomasello \& Farrar, 1986; Topping et al., 2013). Earlier studies have emphasised that both the quantity (Hart \& Risley, 1995; Hoff \& Naigles, 2002; Hurtado et al., 2008; Huttenlocher et al., 2002; Rowe, 2008; Trautman \& Rollins, 2003) and quality or communicative functions of caregiver speech (Camp et al., 2010; Madigan et al., 2019; Rollins, 2003; Zauche et al., 2016; Zimmerman et al., 2009) influence child language outcomes. Quality of caregiver speech is often operationalised in terms of responsiveness (i.e. promptly, contingently and meaningfully responding to the actions or speech of the child) and directiveness (i.e. commanding or controlling the child's behaviour or attention). However, there is mixed evidence regarding whether maternal responsiveness or directiveness still affect language skills at 2 and 3 years, taking into consideration the huge variation in language skills at that age and the gender of the child. At this age, in addition to the dramatic change in language and other cognitive skills, toddlers can stay engaged for longer periods of time and follow the mother's focus, which may lessen the need for maternal scaffolding (Hoff \& Naigles, 2002). Moreover, child autonomy emerges, which may cause mothers to use new ways to communicate with their children (Taylor et al., 2009), and there is also a need for mothers to adapt their input so that the child receives increasingly challenging opportunities for learning (Landry et al., 2003). The recognised female advantage in expressive vocabulary skills of 2- to 3-year-olds may be partly explained by maternal responsiveness and directiveness or the amount of maternal talk towards the different genders. This study extends work on maternal responsiveness and directiveness to a sample of Finnish parents and children.

Responsiveness and its role in child vocabulary development

Responsiveness is conceptualised as prompt, contingent and appropriate reactions displayed to children in the context of everyday exchanges (Ainsworth et al., 1974; 
Bornstein \& Tamis-LeMonda, 1989; Bornstein et al., 2008; Landry et al., 2001). Responses are considered prompt when they follow the actions of the child within a brief time window, and contingent when they are conceptually dependent on child actions (Tamis-LeMonda et al., 2014). Responsiveness is considered to be semantically contingent when the adult and child are jointly attending to the same thing (Tomasello \& Farrar, 1986).

Maternal responsive utterances and semantically contingent maternal communication style have been shown to positively affect language outcomes in children around the age of 1 year (McGillion et al., 2013; Paavola-Ruotsalainen et al., 2018; Rollins, 2003; Trautman \& Rollins, 2003). At the beginning of the second year, verbal responsiveness or responsiveness to either explorations, vocalisations or play results in better vocabulary, expressive and receptive language, syntactic and grammatic abilities, and earlier attainment of language milestones (Camp et al., 2010; Hoff, 2006; Karrass \& Braungart-Rieker, 2003; Roberts \& Kaiser, 2011; Tamis-LeMonda et al., 2001). In a recent meta-analysis of 36 studies on responsiveness and language between the ages of 17 months and 5 years 9 months, the effect size between sensitive responsiveness and child expressive and receptive language was found to be medium (Madigan et al., 2019). In two of the studies of the meta-analysis, maternal sensitive responsiveness correlated with expressive and receptive language in children who started talking late at the age of 24 months (Down et al., 2014), and explained the rate of growth of expressive and receptive language between children's ages of 18 months and 36 months (Pungello et al., 2009). Maternal responsiveness at the children's age of 24 months has also predicted children's receptive and expressive language at 36 months (Hudson et al., 2015). By contrast, some studies have not found associations between maternal responsiveness and children's vocabulary at the age of 24 months or maternal responsiveness at the children's age of 24 months and child expressive or receptive vocabulary at 30 months (Hoff \& Naigles, 2002; Paavola-Ruotsalainen et al., 2018). Hoff and Naigles (2002) concluded that quantity of input, lexical richness and syntactic complexity are important in predicting later vocabulary at this age. 
Directiveness is characterised as attempts to command and control a child's behaviour or attention. Directiveness is thought to shut down conversations, as the child's participation is less welcome than in the responsive style (Pine, 1992; Bloom, 1993). However, it has been argued that if directive utterances are used in a joint attentional focus, they can be considered as supportive and not as insensitive (Akhtar et al., 1991; Flynn \& Masur, 2007; Pine, 1992). Supportive directives are defined as directives that follow the child's attention, while intrusive directives lead the child's attention to a new object or action. Rates of supportive and intrusive directives have been reported to be inversely associated in maternal speech (Flynn \& Masur, 2007; Paavola-Ruotsalainen et al., 2018). Many studies have not separated attention-leading and attention-following directives, which have been shown to have different impacts on the child's linguistic outcome (Flynn \& Masur, 2007; Paavola-Ruotsalainen et al., 2018).

Intrusive behavioural or verbal directives have correlated negatively with productive vocabulary, vocabulary comprehension or language (such as number of words, mean length of utterance and object-labels per minute) between 10 months and 21 months (Hampson \& Nelson, 1993; Masur et al., 2005; Paavola-Ruotsalainen et al., 2018; Tomasello \& Farrar, 1986). Furthermore, mothers' intrusiveness to 2-year-old children has correlated negatively with the children's receptive language at 3 years (TamisLemonda et al., 2004). Additionally, children between 3 years and 4 years 6 months with more intrusive mothers, had lower scores in language comprehension and expression (Keown et al., 2001). Similarly, Podmore (1988) found direct commands to be negatively correlated with language scores of 3-year-olds. By contrast, in some studies maternal attention-leading directives have been reported not to affect language comprehension, vocabulary or referential language for 9-15-month-old children (Baumwell et al., 1997, Carpenter et al., 1998), and behaviour-leading directives have not been associated with child language skills in 2-year-olds (Hoff \& Naigles, 2002).

When considering evidence from attention-following directives and child language, the correlations appear to be positive. Specifically, verbal or behavioural supportive directives have positively predicted children's speech comprehension and gesture use, or vocabulary in the age range of 10 months to 21 months (Masur et al., 2005; Paavola- 
Ruotsalainen et al., 2018). Additionally, supportive directives at 13 months are associated with advances in child language in 22-month-old children (Akhtar et al., 1991). There are very few studies on the relationships between supportive directives and language in older children. In two of these, there were no correlations between maternal supportive directives at 24 months and child receptive and expressive language at 30 months (Paavola-Ruotsalainen et al., 2018) or maternal supportive directives at 24 months and child receptive and expressive language at 36 months (Levickis et al., 2014).

The possible effects of gender

Children differ substantially in their rates of receptive and expressive vocabulary growth (Fenson et al., 1994; Gram Simonsen et al., 2014). On average, at the age of 18 months, children's receptive vocabulary size is around 191 to 250 words (Gram Simonsen et al., 2014; Stolt et al., 2008). Girls tend to have larger receptive vocabularies than boys between the ages of 10 months and 36 months (Bornstein \& Tamis-LeMonda, 1989; Bornstein et al., 2004; Fenson et al., 1994; Zambrana et al., 2012), but there is also contradictory evidence about the receptive vocabulary differences between girls and boys (see e.g. Eriksson et al., 2011). Regarding expressive vocabulary, from around the age of 18 months, the expressive vocabulary size commonly starts to grow rapidly. The mean or the median expressive vocabulary size has been shown to be 225 words at 24 months, 433 words at 30 months (Gatt et al., 2014) and 654 words at 36 months (Gram Simonsen et al., 2014). Similarly to receptive vocabulary, girls have been shown to have larger expressive vocabularies than boys between the ages of 8 months and 39 months (Bornstein et al., 2004; Eriksson et al., 2011; Fenson et al., 1994; Galsworthy et al., 2000; Reilly et al., 2007). For example, at the age of 20 months, the median number of words in expressive vocabulary has been measured to be 69 for boys and 101 for girls (Gram Simonsen et al., 2014).

Regarding maternal responsiveness and directiveness, child gender is also one of the factors to consider. Mothers may provide more responsive speech to girls than to boys (Leaper et al., 1998; Flynn \& Masur, 2007), perhaps because girls speak and understand more (Barnett et al., 2012). Mothers have been evidenced to use more intrusive directives towards boys than towards girls (Flynn \& Masur, 2007), and to talk more to 
their daughters than to their sons (Leaper et al., 1998; Topping et al., 2013). However, in many studies child gender has not affected maternal responsiveness (Hirsh-Pasek et al., 2015; Paavola-Ruotsalainen et al., 2018; Tamis-Lemonda et al., 2001), or the amount of maternal talk (Hirsh-Pasek et al., 2015; Hurtado et al., 2008; Huttenlocher et al., 2002; Paavola-Ruotsalainen et al., 2018).

The present study

Based on previous research, maternal responsiveness still affects child language development at the age of 2 years. With regard to maternal directiveness, intrusive directives seem to have negative effects, and supportive directives positive or no effects, on child language development. The aim of this study was to determine whether maternal responsiveness and directiveness in speech to 2-year-olds is associated with concurrent and later receptive and expressive vocabulary (30 months and 36 months), taking into consideration the huge variation in children's language skills that is evident at this age and the gender of the child.

We sought answers to the following questions:

1. Are there differences in maternal utterance frequencies or categories of responsiveness and directiveness towards boys or girls at the age of 24 months?

2. Are there relationships between the different maternal utterance categories and the total number of utterances?

3. Are there gender differences in receptive or expressive vocabulary at the ages of 24 months, 30 months and 36 months?

4. Are there relationships between the maternal responsive and directive speech at the children's age of 24 months and the children's receptive or expressive vocabulary at the ages of 24 months, 30 months and 36 months?

\section{METHOD}

\section{Participants}


The participants were 60 healthy children (30 boys and 30 girls) and their mothers, who were native speakers of Finnish. They were recruited either from child health clinics during the 18-month check-up, from open family clubs or via social media. In order to participate in the study, the children had to fulfil the following inclusion criteria: (1) full-term birth (gestational weeks 37+) after normal pregnancy and delivery, (2) no diagnosed mental or physical disability or major disorder, (3) no suspicion of autism spectrum disorders, (4) neither diagnosed nor suspected hearing impairment, (5) no malformations in the oral or facial area (e.g. cleft palate). The children were living with both of their biological parents or at least with their biological mother. Families meeting these criteria were selected on the basis of their willingness to participate in a longitudinal study of predictors of child early linguistic development.

At childbirth, maternal age ranged from 21 to 38 years $(M=29.75, \mathrm{SD}=4.13)$. Based on the International Standard Classification of Education (ISCED, 2011), mothers of the present sample had obtained considerably higher education than most 20- to 34-year-old women in Finland in 2017: In our sample, 72\% had some tertiary (e.g., university) education (vs. $32 \%$ of the general female population), 5\% had post-secondary nontertiary (e.g., college) education (vs. $1 \%$ of the general female population), $22 \%$ had upper secondary (e.g. senior secondary school, vocational educational institutions) education (vs. $53 \%$ of the general female population), $2 \%$ had lower secondary (comprehensive school) education (vs. 14\% of the general female population) (Statistics Finland's PX-Web databases, 2016).

\section{Procedure}

At the children's ages of 24 months, 30 months and 36 months, the participants were visited in their homes by the first or the second author. A written informed consent to participate was obtained from the parents. At 24 months each dyad was videotaped for about twenty minutes in a semi-structured free-play session using a standard set of ageappropriate toys. The toy set included e.g. a teddy bear, a shape box, a tea set and a toy car with a driver. The mothers were instructed to interact with their children in the way they usually did. Videotapes were later transcribed verbatim. The basic unit of the transcription was the utterance. An utterance was a continuous piece of speech or vocalisation preceded and followed by a pause of at least two seconds. Whenever 
possible, it was defined on a syntactical basis. Also, fillers and vocalisations, either alone or in conjunction with speech, were defined as utterances. Additionally or in some cases alternatively, changes in conversational turn or topic as well as intonation pattern were considered when marking the utterance boundaries. The transcripts also included nonverbal acts, which served, either alone or in conjunction with vocalisation or speech, to initiate or maintain interaction. These acts were either conventional gestures, different kinds of action behaviours or play activities. Both the maternal and child utterances and nonverbal acts were included in the transcripts. The transcription procedure was managed by the first and the second author, with the help of several Master's students. Discrepancies were resolved by discussion. The transcription reliability was checked so that $20 \%$ of the data was reanalysed by another researcher. The percentage of agreement was $100 \%$ concerning the segmentation of the sequences of words and vocalisations into utterances as well as the inclusion of nonverbal acts in the transcripts. The second author acted as a supervisor of the Master's students and checked all their transcripts. With regard to the assessment of child linguistic abilities, children's vocabulary was assessed during each home visit. The Finnish versions of the Receptive and Expressive One-Word Picture Vocabulary Tests (ROWPVT-4 and EOWPVT-4; Martin \& Brownell, 2011ab) were used.

\section{Measures}

Maternal utterances. From each videotaped free-play session, 15 minutes were analysed with the help of the transcripts, from the beginning of the second minute until the end of the $16^{\text {th }}$ minute. The total number of maternal utterances was counted from the phrases expressed by the mother during the 15-minute play-interaction. Next, the categories of mothers' responsive and directive speech used in the present study were adapted from the earlier work of Flynn and Masur (2007). These four mutually exclusive categories are: Responsive Utterances, Supportive Directive Utterances, Intrusive Behavioural Directives and Intrusive Attentional Directives. In addition, we used a category Other Utterances for those that were not included in any of the above-mentioned categories. Besides considering the mother's pragmatic intent, this categorisation system takes into consideration the mother's sensitivity to the child's focus of attention at the time of the utterance. 
Utterances that referred to an object, action or attribute on which the child was currently visually focused, or with which the child was actively engaged, were identified as following the child's attention, whereas others were designated as leading the child's attention (see Akhtar et al., 1991; Landry et al., 1986; Masur et al., 2005). Pragmatic categorisation reflected the function of the utterance (see Pine, 1992). The definitions of the five categories are as follows (examples are from our corpus, translated into English):

(a) Responsive Utterances are statements describing a person's behaviour, actions, feelings, etc., or an object or an event present in the immediate situation (e.g. "Yes, it is a triangle."; "You are hugging the doll."). They are following the child's focus of attention.

(b) Supportive Directives aim to control the child's physical behaviour by suggesting, commanding or encouraging the child (e.g. "Could I get some more tea, please.") Included in this category are also so-called test questions (e.g. "What is it?"). Supportive Directives are also following the child's focus of attention.

(c) Intrusive Behavioural Directives have the same pragmatic intent as Supportive Directives, but they direct the child's focus of attention away from the object or action with which the child is currently engaged and/or lead the child's behaviour in a new direction.

(d) Intrusive Attentional Directives attempt to redirect or lead the child's focus of attention (e.g. "Oh look, there is a doll there"). Similarly to Responsive Utterances, their pragmatic intent is to describe something.

(e) Other Utterances include so-called fillers (e.g. "Um" "Uh" "I see" "Oh well" "All right" "Like that" "Ok"), that do not convey any referential meaning but appear to be used as responses to maintain interaction. Included in this category are also those maternal utterances that were interrupted for some reason (e.g. "Let's -“). Altogether, in the present data interrupted sentences constituted a very small percentage of utterances.

In the present study, nonverbal acts included in the transcripts are not examined. However, their inclusion in the transcripts was important, because it made it easier to identify the child's focus of attention and, by implication, to categorise maternal utterances. The categorisation was carried out by the first and second author, with the help of several Master's students. In the beginning of this procedure, some parts of the data were viewed together and the principles of categorisation were discussed 
thoroughly. The second author checked the categorisations of the Master's students. Furthermore, $20 \%$ of the data analysed by the first author was re-analysed by the second author.

Coding reliability. The percentage of agreement was $98.47 \%$ (the number of utterances that were categorised in the same way $\div$ the total number of utterances $X 100=$ agreement \%). Cohen's kappa values were also run to determine the level of agreement between the researchers. The value for the data was 0.975 , indicating almost perfect agreement. For the most part, the discrepancy found was between the categories Responsive Utterances and Supportive Directives.

Child vocabulary measures. Receptive and Expressive One-Word Picture Vocabulary Tests (ROWPVT-4 and EOWPVT-4; Martin \& Brownell, 2011ab) were used at the children's ages of 24 months, 30 months and 36 months in order to obtain measures of vocabulary skills. Both tests were originally standardised on English-speaking individuals in the United States. Nowadays they are widely used in the fields of education, speech and language therapy and psychology. Finnish versions were used in the present study. They are currently under validation (see Kunnari \& Välimaa, 2011). Hence, the Finnish standard scores are not yet available. Raw scores were used in the analyses of the present study.

Included in the ROWPVT-4 are 190 pages of full-colour illustrations, four per page. On hearing the word spoken, an individual is asked to choose from four illustrations the one that matches the word. Test items are presented in a developmental sequence. Based on the examinee's age, differential starting points are used. Children at the ages of 24 months and 30 months all start from the beginning. The ROWPVT-4 defines the basal as eight consecutive correct responses and the ceiling as six errors within eight consecutive items. The raw score is the number of correct responses up to the ceiling item. The EOWPVT-4, on the other hand, assesses an individual's ability to name objects, actions and concepts. The test includes 190 full-colour illustrations that are presented to the examinee in a developmental sequence. Like in the ROWPVT-4, agerelated critical-range testing is utilised. Children at ages 24 months and 30 months start from the first item. The EOWPVT-4 defines the basal as eight consecutive correct 
responses and the ceiling as six consecutive errors. The raw score is the number of correct responses up to the ceiling item.

Statistical analyses

Statistical analyses were produced with SPSS version 26.0 for Windows. Mean (M), standard deviation (SD) and ranges were chosen to describe the distribution and amount of variation in the data. The Kolmogorov-Smirnov test was used to examine the distributions of the variables. A few variables deviated to some extent from normal distribution. However, histograms indicated that the distributions of all the variables were at least close to normal. Hence, parametric tests were chosen for the statistical analyses of the data. The possible effects of gender were assessed using the Student's $t$ test for independent samples. Cohen's $d$ was used as a measure of effect size. According to Cohen (1988), $d$ at around 0.8 can be considered as a large effect, whereas $d$ at around 0.5 reflects a medium and 0.2 a small effect.

To examine the relationships between the different maternal utterance categories and the total number of utterances as well as to investigate the relationships between the total number of maternal utterances and child vocabulary measures, Pearson productmoment correlations were used. In the analyses of the relationships between the different maternal utterance categories as well as when examining the relationships between the different utterance categories and child vocabulary measures, the Pearson product-moment correlations as well as partial correlations controlling for the total number of maternal utterances were used. With regard to later vocabulary outcomes, vocabulary at the age of 2 years was also controlled. In the analyses, $p$ values of $<.05$ were considered statistically significant.

\section{RESULTS}

Maternal responsiveness and directiveness to 2-year-old children-descriptive statistics and gender differences 
The descriptive statistics of maternal utterance categories as well as the total number of utterances are presented in Table 1. Mean frequencies, standard deviations, ranges and the significance between group values for these measures are presented for the whole group of children and for boys and girls separately. 
TABLE 1. Descriptives of maternal utterances and the total number of utterances to 2-year-old children

\begin{tabular}{|c|c|c|c|c|}
\hline \multirow[t]{4}{*}{ Maternal utterance category } & All $(\mathrm{N}=60)$ & Boys $(\mathrm{n}=30)$ & Girls $(\mathrm{n}=30)$ & Significance of the \\
\hline & Mean (SD) & Mean (SD) & Mean (SD) & difference between mean \\
\hline & Range & Range & Range & values (two last columns) \\
\hline & & & & $\begin{array}{c}\text { in the groups of girls and } \\
\text { boys }(t, p)\end{array}$ \\
\hline \multirow[t]{2}{*}{ Responsive Utterances $^{\mathrm{a}}$} & $107.25(36.06)$ & $108.70(31.74)$ & $105.80(40.42)$ & $t(58)=0.31$ \\
\hline & $27-207$ & $27-169$ & $27-207$ & $p=.758$ \\
\hline \multirow[t]{2}{*}{ Supportive Directives ${ }^{b}$} & $65.27(26.39)$ & $64.90(28.06)$ & $65.63(25.09)$ & $t(58)=-0.11$ \\
\hline & $17-146$ & $19-146$ & $17-112$ & $p=.951$ \\
\hline \multirow[t]{2}{*}{ Intrusive Behavioural Directives $^{\mathrm{c}}$} & $4.37(5.58)$ & $4.67(6.11)$ & $4.07(5.09)$ & $t(58)=0.41$ \\
\hline & $0-23$ & $0-23$ & $0-20$ & $p=.681$ \\
\hline \multirow[t]{2}{*}{ Intrusive Attentional Directives ${ }^{\mathrm{d}}$} & $2.07(2.62)$ & $2.70(3.25)$ & $1.43(1.61)$ & $t(58)=1.91$ \\
\hline & $0-12$ & $0-12$ & $0-5$ & $p=.061$ \\
\hline \multirow[t]{2}{*}{ Other Utterances ${ }^{\mathrm{e}}$} & $33.27(15.88)$ & $30.27(14.71)$ & $36.27(16.69)$ & $t(58)=-1.49$ \\
\hline & $8-66$ & $10-66$ & $8-65$ & $p=.124$ \\
\hline \multirow[t]{2}{*}{ Total Number of Utterances ${ }^{\mathrm{f}}$} & $211.90(58.79)$ & $211.57(55.14)$ & $212.23(62.76)$ & $t(58)=-0.04$ \\
\hline & $55-363$ & $62-315$ & $55-363$ & $p=.965$ \\
\hline
\end{tabular}

Note. Student's t-test for two independent samples was used. Effect sizes (d-test) were not calculated, because none of the differences between gender groups were statistically significant $(\mathrm{p}<.05)$

Significance of the difference between the scores in the groups of boys and girls: ${ }^{a} 95 \%$ CI $-15.8-21.68$; ${ }^{\text {} 95 \% ~ C I ~}-14.49-13.02$; ${ }^{\mathrm{c}} 95 \%$ CI $-2.30-3.50$; ${ }^{\mathrm{d}} 95 \%$ CI $-0.06-2.59$; ${ }^{\mathrm{e}} 95 \%$ CI $-14.13-2.13 ;{ }^{\text {f }} 95 \%$ CI $-31.31-29.98$ 
There was considerable individual variation in both the number and categories of maternal utterances. Nevertheless, on average mothers used considerably more Responsive Utterances and Supportive Directives than Intrusive Behavioural or Intrusive Attentional Directives in their speech. The possible effects of gender were investigated using the Student's $t$-test for independent samples. There were no differences in mothers' total numbers of utterances or utterance categories in their speech directed towards the different genders. Nevertheless, there was a trend that mothers used more Intrusive Attentional Directives towards boys than girls.

Relationships between the total number of utterances and the different utterance categories

Pearson product-moment correlations were used to examine the possible relationships between the total number of utterances and the different utterance categories. There were statistically significant correlations between the total number of utterances and Responsive Utterances $(r=0.833, p<.001)$, Supportive Directives $(r=0.765, \mathrm{p}<.001)$ and Other Utterances $(r=0.499, p<.001)$. By contrast, there were no statistically significant correlations between the total number of utterances score and the utterance categories of Intrusive Behavioural Directives or Intrusive Attentional Directives. The correlation coefficients were very low.

Next we studied the correlations between the different utterance categories of the mothers. The partial correlations controlling for the total number of utterances are presented in Table 2. Several statistically significant relationships, either positive or negative, were found. 
TABLE 2. Pearson product-moment correlations and partial correlations, controlling for the total number of utterances, between maternal responsive and directive utterance frequencies at the children's age of 2 years.

\begin{tabular}{|c|c|c|c|c|}
\hline & (2) & (3) & (4) & (5) \\
\hline (1) Responsive & .407 & -.123 & -.093 & .226 \\
\hline \multirow[t]{3}{*}{ Utterances } & $(<.001)^{* * *}$ & $(.350)$ & $(.478)$ & $(.082)$ \\
\hline & -.647 & -.390 & -.182 & -.397 \\
\hline & $(<.001) * * *$ & $(.002) * *$ & $(.167)$ & $(.002) * *$ \\
\hline (2) Supportive & & .149 & -.042 & .206 \\
\hline \multirow[t]{3}{*}{ Directives } & & $(.257)$ & $(.748)$ & $(.114)$ \\
\hline & & .101 & -.076 & -.315 \\
\hline & & $(.445)$ & $(.566)$ & $(.015) *$ \\
\hline (3) Intrusive & & & .536 & -.002 \\
\hline Behavioural & & & $(<.001) * * *$ & $(.989)$ \\
\hline \multirow[t]{2}{*}{ Directives } & & & .538 & -.066 \\
\hline & & & $(<.001) * * *$ & $(.621)$ \\
\hline (4) Intrusive & & & & -.057 \\
\hline Attentional & & & & $(.663)$ \\
\hline \multirow[t]{2}{*}{ Directives } & & & & -.071 \\
\hline & & & & $(.591)$ \\
\hline \multicolumn{5}{|l|}{ (5) Other } \\
\hline Utterances & & & & \\
\hline
\end{tabular}

Note. $\mathrm{P}$-values are in parentheses.

Note. ${ }^{*} \mathrm{p}<.05 ; * * \mathrm{p}<.01 ; * * * \mathrm{p}<.001$.

A significantly negative correlation was found between Responsive Utterances and Supportive Directives. Quite interestingly, the Pearson product-moment correlation before controlling for the maternal total number of utterances was positive, whereas the partial correlation was negative. Furthermore, a negative partial correlation was found between Responsive Utterances and Intrusive Behavioural Directives as well as Responsive Utterances and Other Utterances. A negative partial correlation was also observed between Supportive Directives and Other Utterances. In contrast, there was a positive partial correlation between Intrusive Behavioural Directives and Intrusive Attentional Directives. 
Vocabulary development at 24 months, 30 months and 36 months - descriptive statistics and gender differences

The mean frequencies, standard deviations, ranges and the significance between group values for children's receptive and expressive vocabularies at the ages of 24 months, 30 months and 36 months are presented in Table 3. Again, the descriptives of the whole group of children as well as the groups of boys and girls separately are presented. 
TABLE 3. Descriptives of children's receptive and expressive vocabulary scores at 24 months, 30 months and 36 months.

\begin{tabular}{|c|c|c|c|c|}
\hline \multirow[t]{3}{*}{ Vocabulary measure } & All $(\mathrm{N}=60)$ & Boys $(n=30)$ & Girls $(n=30)$ & Significance of the difference between \\
\hline & Mean (SD) & Mean (SD) & Mean (SD) & mean values (two last columns) in the \\
\hline & Range & Range & Range & groups of girls and boys $(t, p, d)$ \\
\hline \multicolumn{5}{|l|}{24 months } \\
\hline \multirow[t]{2}{*}{ ROWPVT-4 ${ }^{\mathrm{a}}$} & $25.77(8.31)$ & $22.67(6.38)$ & $28.87(8.95)$ & $t(58)=-3.09$ \\
\hline & $14-50$ & $14-37$ & $17-50$ & $p=.003^{* *}, d=0.80$ \\
\hline \multirow[t]{2}{*}{ EOWPVT-4 ${ }^{\mathrm{b}}$} & $13.42(9.36)$ & $9.47(9.13)$ & $17.37(8.95)$ & $t(58)=-3.58$ \\
\hline & $0-33$ & $0-23$ & $0-33$ & $p=.001^{* *}, d=0.87$ \\
\hline \multicolumn{5}{|l|}{30 months } \\
\hline \multirow[t]{2}{*}{ ROWPVT-4c } & $40.27(9.37)$ & $36.43(8.76)$ & $44.10(8.45)$ & $t(58)=-3.45$ \\
\hline & $21-61$ & $21-53$ & $32-61$ & $p=.001^{* *}, d=0.89$ \\
\hline \multirow[t]{2}{*}{ EOWPVT-4 ${ }^{\mathrm{d}}$} & $28.08(12.32)$ & $22.20(11.72)$ & $33.97(10.00)$ & $t(58)=-4.18$ \\
\hline & $0-56$ & $0-38$ & $19-56$ & $p<.001^{* * *}, d=1.08$ \\
\hline \multicolumn{5}{|l|}{36 months } \\
\hline \multirow[t]{2}{*}{ ROWPVT-4 ${ }^{\mathrm{e}}$} & $50.98(11.15)$ & $46.73(7.21)$ & $55.23(12.80)$ & $t(58)=-3.17$ \\
\hline & $24-85$ & $34-69$ & $24-85$ & $p=.002 * *, d=0.82$ \\
\hline \multirow[t]{2}{*}{ EOWPVT-4 ${ }^{\mathrm{f}}$} & $39.13(12.71)$ & $34.13(12.67)$ & $44.13(10.79)$ & $t(58)=-3.29$ \\
\hline & $1-69$ & $1-54$ & $24-69$ & $p=.002 * *, d=0.85$ \\
\hline
\end{tabular}

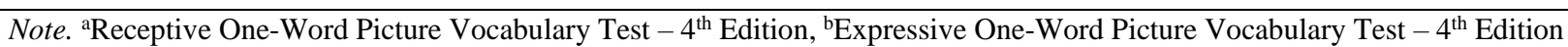

Note. Student's t-test for two independent samples was used. Effect size (d-test) was calculated if the difference was statistically significant $(\mathrm{p}<.05)$.

Note. $* \mathrm{p}<.05 ; * * \mathrm{p}<.01 ; * * * \mathrm{p}<.001$.

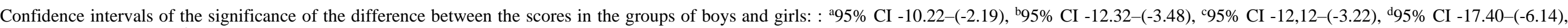
e95\% CI -13.87-(-3.13), f95\% CI -16.08-(-3.92) 
Girls scored higher than boys in both receptive and expressive vocabulary measures at all three age points. The Student's $t$-test for independent samples indicated statistically significant group differences in all the vocabulary measures. The effect sizes were large.

\section{Relationships between maternal responsive and directive utterances and child} vocabulary outcomes

Using Pearson product-moment correlations, no statistically significant relationships were observed between the total number of maternal utterances at the children's age of 24 months and child vocabulary measures at 24 months, 30 months and 36 months. The correlation coefficients were very low. Possible relationships between the maternal utterance categories and the measures of receptive and expressive vocabulary were investigated using Pearson correlations as well as partial correlations. The results are presented in Tables 4 and 5.

TABLE 4. Pearson product-moment correlations and partial correlations, controlling for total utterance frequencies and child vocabulary at 24 months, between the maternal utterance categories at the children's age of 24 months and child receptive vocabulary at 24 months, 30 months and 36 months.

\begin{tabular}{lccc}
\hline \multirow{2}{*}{ Utterance category } & \multicolumn{3}{c}{ ROWPVT-4 (age level) } \\
\cline { 2 - 4 } Responsive Utterances & 24 months & 30 months & 36 months \\
Supportive Directives & $-.042(.748)$ & $.051(.698)$ & $-.185(.156)$ \\
& $-.177(.180)$ & $.186(.167)$ & $-.002(.986)$ \\
Intrusive Behavioural & $-.077(.558)$ & $-.058(.660)$ & $-.197(.131)$ \\
Directives & $.002(.991)$ & $-.190(.147)$ & $-.037(.776)$ \\
Intrusive Attentional & $-.006(.965)$ & $-.278(.036)^{*}$ & $-.014(.916)$ \\
Directives & $-.095(.471)$ & $-.206(.114)$ & $-.054(.680)$ \\
Other Utterances & $-.096(.471)$ & $-.187(.163)$ & $.020(.884)$ \\
& $.438(<.001)^{* * *}$ & $.288(.026)^{*}$ & $.202(.121)$ \\
& $.468(<.001)^{* * *}$ & $-.053(.696)$ & $.105(.438)$ \\
\hline
\end{tabular}

Note. $\mathrm{P}$-values are in parentheses.

Note. $* \mathrm{p}<.05 ; * * \mathrm{p}<.01 ; * * * \mathrm{p}<.001$. 
The Maternal Other Utterances category was positively related to the children's receptive vocabulary at 24 months and 30 months. With regard to partial correlations, at 24 months, a positive relationship was found between Other Utterances and receptive vocabulary when controlling for maternal utterance frequencies. A negative correlation was found between Intrusive Behavioural Directives and receptive vocabulary at the age of 30 months. By contrast, none of the maternal utterance categories were related to child expressive vocabulary at any age point (see Table 5).

TABLE 5. Pearson product-moment correlations and partial correlations, controlling for total utterance frequencies and child vocabulary at age 24 months, between the maternal utterance categories at the children's age of 24 months and child expressive vocabulary at 24 months, 30 months and 36 months.

\begin{tabular}{lccc}
\hline \multirow{2}{*}{ Utterance category } & \multicolumn{3}{c}{ EOWPVT-4 (age level) } \\
\cline { 2 - 4 } Responsive Utterances & 24 months & 30 months & 36 months \\
& $-.200(.125)$ & $-.058(.657)$ & $-.157(.232)$ \\
Supportive Directives & $-0.120(.366)$ & $.124(.358)$ & $-.041(.761)$ \\
& $-.111(.400)$ & $-.036(.784)$ & $-.076(.563)$ \\
Intrusive Behavioural & $.021(.876)$ & $.080(.557)$ & $.070(.607)$ \\
Directives & $-.053(.688)$ & $-.143(.275)$ & $-.045(.734)$ \\
Intrusive Attentional & $-.036(.787)$ & $-.181(.178)$ & $-.023(.866)$ \\
Directives & $-.130(.324)$ & $-.013(.920)$ & $.018(.894)$ \\
Other Utterances & $-.130(.327)$ & $.134(.320)$ & $.138(.304)$ \\
& $.062(.637)$ & $.077(.560)$ & $.125(.343)$ \\
& $.167(.205)$ & $-.231(.084)$ & $-.030(.824)$ \\
\hline
\end{tabular}

Note. P-values are in parentheses.

Pearson product-moment and partial correlations were investigated separately in the two gender groups. In the group of boys, there was a significant negative correlation between maternal use of Intrusive Behavioural Directives and receptive vocabulary at 30 months $(r=-0.347, p=.039)$. The result remained significant when the total utterance frequencies and child vocabulary at 24 months were controlled $\left(r_{x y . z}=-0.435\right.$, $p=.024)$. In contrast, in the group of girls, there was a statistically significant correlation between maternal Other Utterances and receptive vocabulary at 24 months $(r$ $=0.537, p=.002$ ). Partial correlation that controlled for utterance frequency, was also 
positive $\left(r_{x y . z}=0.547, p=.002\right)$. Quite surprisingly, among girls there was a correlation between maternal Intrusive Attentional Directives and expressive vocabulary at the age of 30 months $\left(r_{x y . z}=0.422, p=.029\right)$ when total utterance frequency and child vocabulary at 24 months were controlled.

\section{DISCUSSION}

The purpose of the present study was to determine whether there are relationships between maternal responsiveness and directiveness at the children's age of 24 months and child receptive and expressive vocabulary at ages 24 months, 30 months and 36 months - taking into consideration the high individual variation in vocabulary skills and also child gender. We used the five categories introduced by Flynn and Masur (2007) in categorising responsiveness and directiveness. These categories take into consideration both the attentional focus of the dyad and the pragmatic intent of the mother.

We found no differences in the number of maternal utterances towards girls or boys at the age of 2 years, although individual variation in the amount of speech was extensive. Thus, our findings supported the previous finding that mothers produced the same amount of utterances towards both genders (Hirsh-Pasek et al., 2015; PaavolaRuotsalainen et al., 2018; Tamis-LeMonda et al., 2001). Furthermore, the utterance categories used towards both genders were similar, as found in many previous studies (Hirsh-Pasek et al., 2015; Hurtado et al., 2008; Huttenlocher et al., 2002; PaavolaRuotsalainen et al., 2018; Tamis-LeMonda et al., 2001). However, a trend was found that mothers used more Intrusive Attentional Directives towards boys than girls, as previously reported by Flynn and Masur (2007). Altogether, mothers used mostly Responsive Utterances, followed by Supportive Directives and Other Utterances. The use of attention-leading directives was very infrequent; most mothers used only a few of these during the 15-minute videotaping. Similarly to some previous studies, the mothers with higher numbers of utterances, had higher numbers of utterances in the categories of Responsive Utterances and Supportive Directives (Masur et al., 2005; PaavolaRuotsalainen et al., 2018; Rowe, 2008), and in the category of Other Utterances. 
We found no correlations between maternal verbal responsiveness at the children's age of 24 months and child receptive and expressive vocabulary at 24 months, 30 months and 36 months. Several studies have suggested that maternal responsiveness at the age of 24 months has an impact on the vocabulary development of children, both concurrently and subsequently (Down et al., 2014, Hudson et al., 2015; Madigan et al., 2019). However, Paavola-Ruotsalainen and her group (2018) found no relationship between maternal responsiveness at the children's age of 24 months and language outcomes at 30 months using the method of Flynn and Masur (2007). Furthermore, Hoff and Naigles (2002) concluded that at the age of 18 months and 29 months, when children can follow the attention of the communication partner, responsiveness does not play as big of a role as at earlier ages. With regard to directiveness, maternal Intrusive Behavioural Directives were negatively associated with receptive vocabulary at the age of 30 months in the whole group of children and in the group of boys. This was also true when child vocabulary at 24 months and the total number of maternal utterances were accounted for. However, these correlations were not very strong. Negative correlations between attention-leading directives and receptive language have been found in many other studies (see e.g. Down et al., 2014; Pungello et al., 2009; Tamis-LeMonda et al., 2004), but there is also contradictory evidence (Baumwell et al., 1997; Carpenter et al., 1998; Hoff \& Naigles, 2002). Furthermore, maternal Other Utterances correlated with children's receptive vocabulary at the age of 24 months. The correlation remained significant also at the age of 30 months before controlling for child vocabulary at 24 months, and the number of maternal utterances. Integrated pretend play skills, that quite often go together with linguistic abilities, might have a role in explaining this finding. Rather than talking more, mothers may encourage input from the child through the use of fillers like, 'oh?'. Surprisingly, in the group of girls, maternal Intrusive Attentional Directives correlated positively with expressive vocabulary at the age of 30 months. This unexpected finding may be explained by the fact that Intrusive Attentional Directives was the most infrequently used category in maternal speech. Twelve of the 30 mothers of girls used no Intrusive Attentional Directives in their speech, which may explain the unexpected positive correlation. Altogether, this study seemed to support the notions that responsive parenting might affect receptive language more than expressive language (Reznick, 1997), and that child gender may moderate interactions between responsiveness and language (Barnett et al., 2012). 
In the present study, statistically significant gender differences were evidenced in both receptive and expressive vocabulary at the ages of 24 months, 30 months and 36 months. There is a consensus on a gender difference in expressive language skills at an early age (Bornstein et al., 2004; Eriksson et al., 2011; Fenson et al. 1994; Galsworthy et al., 2000; Reilly et al., 2007). Not all, but many studies have found the gender difference also in receptive language (Bornstein et al., 2004; Fenson et al., 1994; Zambrana et al., 2012). In our study, the effect sizes for the gender differences in both receptive and expressive vocabulary scores were large. In previous studies, the effect size between receptive language and gender has mostly been small (see e.g. Eriksson et al., 2011), though some work has found larger effects (Zambrana et al., 2012).

There are limitations to this study that should be taken into account when interpreting the results. Even though we studied interactions in the most natural kind of setting, at the children's homes, interactions have been shown to be situation specific (see e.g. Bornstein et al., 2008). The results regarding responsiveness and directiveness in this study relate to a very specific, controlled and brief situation: a child centred dyadic play activity with limited objects in type and number followed by an observer. Everyday situations in which children participate may differ to a varying degree from those controlled activities. Furthermore, the sample was homogenous and the mothers were above-average educated, which might have affected our results, as the relationships between responsiveness, directiveness and language are considered to be stronger in high-risk or in socio-economically lower status populations (Landry et al., 2001; Landry et al., 2003; Madigan et al., 2019). Because some of the relationships that we found are not very strong they might not have survived a Bonferroni correction. However, a correction was not performed, because the sample size is rather small and therefore there is also the potential to mask true significant findings. We studied only vocabulary, whereas there might be other linguistic, communicative, cognitive and social-emotional aspects of child development on which responsiveness could have a stronger effect. It also seems that more global measures of responsiveness bring forth more relationships between maternal responsiveness, directiveness and child language. Mesman (2010) suggested that micro-level maternal contingency and macro-level maternal sensitivity might not be related and might even measure different constructs. However, the percentage of agreement of the maternal utterance categorisations used in the present 
study is very high, and the categories appear to instantiate differences that may lead to different linguistic outcomes.

Nevertheless, our study provides new information on mothers' responsiveness and directiveness and child vocabulary skills in a Finnish language community. Responsiveness and directiveness are most preferably studied across multiple age points with larger sample sizes and with both second-by-second and more global measures. Furthermore, gender appears to have important implications when screening for early language skills and maternal responsiveness and directiveness. An interesting next step would be to see how the child influences the parent during the interaction process. Slow-to-talk children have been found to be significantly less responsive and assertive towards their mothers (Bonifacio et al., 2007), which may result in fewer opportunities for the parent to use e.g. responsive language, and consequently affect children's linguistic, communicative, cognitive and social-emotional capabilities. 


\section{REFERENCES}

Ainsworth, M. D. S., Bell, S. M. \& Stayton, D. (1974). Infant-mother Attachment and Social Development: Socialization as a Product of Reciprocal Responsiveness to Signals. Cambridge University Press.

Akhtar, N., Dunham, F. \& Dunham, P. (1991). Directive interactions and early vocabulary development: The role of joint attentional focus. Journal of Child Language, $18,41-49$.

Barnett, M. A., Gustafsson, H., Deng, M., Mills-Koonce, W. R. \& Cox, M. (2012). Bidirectional associations among sensitive parenting, language development and social competence. Infant and Child Development, 21, 374-393.

Baumwell, L., Tamis-LeMonda, C. S. \& Bornstein, M. H. (1997). Maternal verbal sensitivity and child language comprehension. Infant Behavior and Development, 20, 247-258.

Bloom, L. (1993). The Transition from Infancy to Language: Acquiring the Power of expression. Cambridge University Press.

Bonifacio, S., Girolametto, L., Bulligan, M., Callegari, M., Vignola, S. \& Zocconi, E. (2007). Assertive and responsive conversational skills of Italian-speaking late talkers. International Journal of Language \& Communication Disorders, 43, 607-623.

Bornstein, M. H. \& Tamis-LeMonda, C. S. (1989). Maternal responsiveness and cognitive development in children. New Directions for Child and Adolescent Development, 43, 1-103.

Bornstein, M. H., Hahn, C.-S. \& Haynes, M. O. (2004). Specific and general language performance across childhood: Stability and gender considerations. First Language, 24, 267-304.

Bornstein, M. H., Tamis-LeMonda, C. S., Hahn, C.-S. \& Haynes, M. O. (2008). Maternal responsiveness to young children at three ages: Longitudinal analysis of a multidimensional, modular and specific parenting construct. Developmental Psychology, 44, 867-874.

Camp, B. W., Cunningham, M. \& Berman, S. (2010). Relationship between the cognitive environment and vocabulary development during the second year of life. Archives of Pediatrics and Adolescent Medicine, 164, 950-956.

Carpenter, M., Nagell, K. \& Tomasello, M. (1998). Social cognition, joint attention, and communicative competence from 9 to 15 months of age. Monographs of the society for research in child development, $63,1-174$.

Cohen, J. (1988). Statistical Power Analysis for the Behavioral Science. Lawrence Erlbaum Associates, 77-83.

Down, K., Levickis, P., Hudson, S., Nicholls, R. \& Wake, M. (2014). Measuring maternal responsiveness in a community-based sample of slow-to-talk toddlers: a crosssectional study. Child: Care, Health and Development, 41, 329-333.

Eriksson, M., Marschik, P. B., Tulviste, T., Almgren, M., Pereira, M., Wehberg, S., Marjanovic-Umek, L., Gayraud, F., Kovacevic, M. \& Gallego, C. (2011). Differences 
between girls and boys in emerging language skills: Evidence from 10 language communities. British Journal of Developmental Psychology, 30, 326-343.

Fenson, L., Dale, P. S., Reznick, J. S., Bates, E., Thal, D. J. \& Pethick, S. J. (1994). Variability in early communicative development. Monographs of Social Research on Child Development, 59, 1-173; 173-185.

Flynn, V. \& Masur, E. (2007). Characteristics of maternal verbal style: responsiveness and directiveness in two natural contexts. Journal of Child Language, 34, 519-543.

Galsworthy, M. J., Dionne, G., Dale, P. S. \& Plomin, R. (2000). Sex differences in early verbal and non-verbal cognitive development. Developmental science, 3, 206-215.

Gatt, D., Grech, H. \& Dodd, B. (2014). Early expressive vocabulary skills: A multimethod approach to measurement. First Language, 34, 136-54.

Gram Simonsen, H., Kristofferssen, K. E., Bleses, D., Wehberg, S. \& Jorgensen, R. N. (2014). First Language, 34, 3-23.

Hampson, J. \& Nelson, K. (1993). The relation of maternal language to variation rate and style of language acquisition. Journal of Child Language, 20, 313-342.

Harlaar, N., Hayio-Thomas, M. E., Dale, P. S. \& Plomin, R. (2008). Why do preschool abilities correlate with later reading? A twin study. Journal of Speech, Language and Hearing Research, 51, 688-705.

Hart, B. \& Risley, T. R. (1995). Meaningful differences in the everyday experience of young American children. Paul H. Brookes Publishing.

Hirsh-Pasek, K., Adamson, L. B. \& Bakeman, R. (2015). The contribution of early communication quality to low-income children's language success. Psychology Science, $26,1071-1083$.

Hoff, E. (2006). How social contexts support and shape language development. Developmental Review, 26, 55-88.

Hoff, E. \& Naigles, L. (2002). How children use input to acquire a lexicon. Child Development, 73, 418-433.

Hudson, S., Levickis, P., Down, K., Nicholls, R. \& Wake, M. (2015). Maternal responsiveness predicts child language at ages 3 and 4 in a community-based sample of slow-to-talk toddlers. International Journal of Language and Communication Disorders, 50, 136-142.

Hurtado, N., Marchman, V. A. \& Fernald, A. (2008). Does input influence uptake? Links between maternal talk, processing speed and vocabulary size in Spanish-learning children. Developmental Science, 11, 31-39.

Huttenlocher, J., Vasilyeva, M., Cymerman, E. \& Levine, S. (2002). Language input and child syntax. Cognitive Psychology, 45, 337-374.

ISCED (2011). Operational Manual. Guidelines for classifying national educational programmes and related qualifications. European Union. 
Karrass, J. \& Braungart-Rieker, J. M. (2003). Parenting and temperament as interacting agents in early language development. Parental Science Practices, 3, 235-259.

Keown, L. J., Woodward, L. J. \& Field, J. (2001). Language development of pre-school children born to teenage mothers. Infant and Child Development, 10, 129-135.

Kunnari, S. \& Välimaa, T. (2011). Lasten ymmärtävän sanaston arviointi kuvasanavarastotestillä. In S. Stolt, M. Lehtihalmes, L. M. Heikkola, \& S. Kunnari (Eds.), Lasten ja nuorten puheen ja kielen arviointi ja mittaaminen (pp. 108-117). Helsinki, Finland: Puheen ja kielen tutkimuksen yhdistyksen julkaisuja 43.

Landry, S. H., Chapienski, M. L. \& Schmidt, M. (1986). Effects of maternal attentiondirecting strategies on preterms' response to toys. Infant Behavior and Development, 9, 257-269.

Landry, S. H., Smith, K. E., Swank, P. R., Assel, M. A. \& Vellet, S. (2001). Does early responsive parenting have a special importance for children's development or is consistency across early childhood necessary? Developmental Psychology, 37, 387-403.

Landry, S. H., Smith, K. E. \& Swank, P. R. (2003). The importance of parenting during early childhood for school-age development. Developmental Neuropsychology, 24, 559-591.

Leaper, C., Anderson, K. J. \& Sanders, P. (1998). Moderators of gender effects on parents' talk to their children: A meta-analysis. Developmental Psychology, 34, 3-27.

Levickis, P., Reilly, S., Girolametto, L., Ukoumunne, O. \& Wake, M. (2014). Maternal behaviors promoting language acquisition in slow-to-talk toddlers: prospective community-based study. Journal of Developmental \& Behavioral Pediatrics, 35, 274 281.

Madigan, S. L., Prime, H., Graham, S., Rodrigues, M., Anderson, N., Khoury, J. E \& Jenkins, J. M. (2019). Parenting behavior and child language: A meta-analysis. American Academy of Pediatrics, 144, 1-14.

Martin, N. \& Brownell, R. (2011a). Receptive One-Word Picture Vocabulary Test, $4^{\text {th }}$ Edition. Academic Therapy Publications.

Martin, N. \& Brownell, R. (2011b). Expressive One-Word Picture Vocabulary Test, $4^{\text {th }}$ Edition. Academic Therapy Publications.

Masur, E. F., Flynn, V. \& Eichorst, D. L. (2005). Maternal responsive and directive behaviours and utterances as predictors of children's lexical development. Journal of Child Language, 23, 63-91.

McGillion, M. L., Herbert, J. S., Pine, J. M., Keren-Portnoy, T., Vihman, M. M. \& Matthews, D. E. (2013). Supporting early vocabulary development: what sort of responsiveness matters? IEEE Transactions in on Autonomous Mental Development, 5, 240-248.

Mesman, J. (2010). Maternal responsiveness to infants: comparing micro- and macrolevel measures. Attachment \& Human Development, 12, 143-149.

Oliver, B., Dale, P. S. \& Plomin, R. (2004). Verbal and nonverbal predictors of early language problems: an analysis of twins in early childhood back to infancy. Journal of Child Language, 31, 609-631. 
Paavola-Ruotsalainen, L., Lehtosaari, J., Palomäki, J. \& Tervo, I. (2018). Maternal verbal responsiveness and directiveness: consistency, stability and relations to child early linguistic development. Journal of Child Language, 45, 319-339.

Pine, J. (1992). Maternal style at the one-word stage: re-evaluating the stereotype of the directive mother. First Language, 12, 169-186.

Podmore, V. N. (1988). Mothers' interactive behaviours and their children's pre-school assessments: Relationships and issues. New Zealand Journal of Educational Studies, 23, $165-174$.

Pungello, E. P., Iruka, I. U. Dotterer, A. M., Mills-Koonce, R. \& Reznick, J. S. (2009). The effects of socioeconomic status, race and parenting on language development in early childhood. Developmental Psychology, 45, 544-557.

Reilly, S., Wake, M., Bavin, E. L., Prior, M., Williams, J, Bretherton, L., Eadie, P., Barrett, Y. \& Ukoumunne, O. C. (2007). Predicting language at 2 years of age: a prospective community study. Pediatrics, 120, 1441-1449.

Reznick, J. S. (1997). Intelligence, language, nature and nurture in young twins. Cambridge University Press.

Roberts, M. Y. \& Kaiser, A. P. (2011). The effectiveness of parent-implemented language interventions: a meta-analysis. American Journal of Speech-Language Pathology, 20, 180-199.

Rollins, P. R. (2003). Caregivers' contingent comments to 9-month-old infants: Relationships with later language. Applied Psycholinguistics, 24, 221-234.

Rowe, M. L. (2008). Child-directed speech: relations to socio-economic status, knowledge of child development and child vocabulary skill. Journal of Child Language, $35,185-205$.

Statistics Finland's PX-Web databases (2016). Population aged 15 or over by level of education, municipality, gender and age 1970-2016. (2018, August 27):

https://pxnet2.stat.fi/PXWeb/pxweb/en/StatFin/StatFin_kou_vkour/statfin_vkour_pxt 12br.px/

Stolt, S., Haataja, L., Lapinleimu, H. \& Lehtonen, L. (2008). Early lexical development of Finnish children: a longitudinal study. First Language, 28, 259-279.

Tamis-LeMonda, C. S., Bornstein, M. H. \& Baumwell, L. (2001). Maternal responsiveness and children's achievement of language milestones. Child Development, $72,748-767$.

Tamis-LeMonda, C. S., Kuchirko, Y. \& Song, L. (2014). Why is infant language learning mediated by parental responsiveness? Current Directions in Psychological Science, 23, 121-126.

Tamis-LeMonda, C. S., Luo, R., McFadden, K. E., Bandel, E. T. \& Vallotton C. (2019). Early home learning environment predicts children's 5th grade academic skills. Applied Developmental Science, 23, 153-169. 
Tamis-LeMonda, C. S., Shannon, J. D., Cabrera, N. J. \& Lamb, M. E. (2004). Fathers and mothers at play with their 2- and 3-year-olds: contributions to language and cognitive development. Child Development, 75, 1806-1820.

Taylor, N., Donovan, W., Miles, S. \& Leavitt, L. (2009). Maternal control strategies, maternal language usage and children's language usage at two years. Journal of Child Language, 36, 381-404.

Tomasello, M. \& Farrar, J. (1986). Joint attention and early language. Child Development, 57, 1454-1463.

Topping, K., Dekhinet, R. \& Zeedyk, S. (2013). Parent-infant interaction and children's language development. Educational Psychology, 33, 391-426.

Trautman, C. H. \& Rollins, P. R. (2003). Child-centered behaviors of caregivers with 12-month-old infants: association with passive joint engagement and later language. Applied Psycholinguistics, 27, 447-463.

Zambrana, I. M., Ystrom, E. \& Pons, F. (2012). Impact of gender, maternal education, and birth order on the development of language comprehension: a longitudinal study from 18 to 36 months of age. Journal of Developmental and Behavioral Pediatrics, 33, $146-155$.

Zauche, L. H., Thul T., Mahoney, A. E. D. \& Stapel-Wax, J. L. (2016). Influence of language nutrition on children's language and cognitive development: an integrated review. Early Childhood Research Quarterly, 36, 318-333.

Zimmerman, F. J., Gilkerson, J., Richards, J. A., Chistakis, J. A., Dongxin, X., Sharmistha, G. \& Yapanel, U. (2009). Teaching by listening: the importance of adultchild conversations to language development. Pediatrics, 124, 342-349. 